\title{
AMAMENTAÇÃO PARA MÃES PRIMÍPARAS: PERSPECTIVAS E INTENCIONALIDADES DO ENFERMEIRO AO ORIENTAR
}

Inez Silva Almeida ${ }^{1}$, Íris Bazílio Ribeiro ${ }^{2}$, Benedita Maria Rêgo Deusdará Rodrigues ${ }^{3}$, Carolina Cabral Pereira da Costa ${ }^{4}$, Natália dos Santos Freitas ${ }^{4}$ Elis Billion Vargas ${ }^{5}$

\begin{abstract}
RESUMO: No cotidiano assistencial encontramos mulheres que se sentem inseguras diante do desafio de ser nutriz. Assim, o enfermeiro deve agir como facilitador, fornecendo informação e cuidado. Baseados nesta premissa, realizamos um estudo cujo objeto foi a orientação do enfermeiro às mães primíparas, com o objetivo de compreender os motivos-para do enfermeiro ao orientar primíparas sobre amamentação. Como metodologia nos apropriamos da pesquisa qualitativa, utilizando a fenomenologia sociológica de Alfred Schütz. O cenário foi uma Maternidade-Escola, situada no Rio de Janeiro e os sujeitos, os enfermeiros atuantes no Programa de Aleitamento Materno da unidade. Evidenciou-se como resultado que o enfermeiro, ao orientar as primíparas sobre amamentação, espera incentivar a amamentação e alertar sobre suas dificuldades e complicações. Conclui-se que os enfermeiros, na assistência às mães primíparas, podem promover um cuidado diferenciado orientando acerca do aleitamento, assistindo em um contexto biopsicossocial, desvendando mitos e crenças sobre a amamentação.
\end{abstract}

PALAVRAS-CHAVE: Enfermagem; Aleitamento materno; Orientação.

\section{BREASTFEEDING FOR PRIMIPAROUS MOTHERS: NURSE'S PERSPECTIVES AND INTENTIONS WHILE ORIENTING}

\begin{abstract}
In the daily assistance daily we meet women that feel unsafe before the challenge of being nutritious. Thus, the nurse must act as facilitator, providing information and care. Based on this premise we developed a study which object was the nurse's orientation to the primaparous mother, the objective was to understand the nurse's reasons-for while orienting breastfeeding to primiparous women. It was used the qualitative research as methodology, using the Alfred Schütz's phenomenological approach. The research setting was a School-Maternity, located in Rio de Janeiro and the subjects, the Nurses working in the Maternal Breastfeeding Program of this unit. The results showed nurses' expectations when orienting the primiparous about breastfeeding: to foster breastfeeding and alert about its difficulties and complications. In conclusion, nurses when assisting primiparous mothers could promote a differentiated care by orienting about breastfeeding, assisting in a biopsychosocial context, unveiling myths and beliefs about breastfeeding.
\end{abstract}

KEYWORDS: Nursing; Breast feeding; Orientation.

\section{LACTANCIA PARA MADRES PRÍMÍPARAS: PERSPECTIVAS E INTENCIONES DEL ENFERMERO AL ORIENTAR}

RESUMEN: En el cotidiano asistencial encontramos mujeres que se sienten inseguras delante del desafío de ser lactante. Así, el enfermero debe actuar como facilitador, proporcionando información y cuidado. Basados en esta premisa realizamos un estudio cuyo objeto fue la orientación del enfermero a las madres primíparas, teniendo como objetivo comprender los motivos-para del enfermero al orientar primíparas sobre lactación. Como metodología nos apropiamos de investigación cualitativa, utilizando la fenomenología sociológica de Alfred Schütz. El escenario fue una Maternidad-Escuela, situada en Rio de Janeiro y los sujetos, enfermeros actuantes en el Programa de Lactación Materna de la unidad. Se evidenció como resultado que el enfermero, al orientar las primíparas sobre lactación, espera incentivar la lactación y alertar sobre sus dificultades y complicaciones. Se concluye que los enfermeros, en la asistencia a las madres primíparas, pueden promover un cuidado diferenciado orientando acerca de la lactación, asistiendo en un contexto biopsicosocial desvendando mitos y creencias sobre lactación.

PALABRAS CLAVE: Enfermería; Lactancia materna; Orientación.

${ }^{1}$ Enfermeira. Mestre em Enfermagem. Doutoranda da Escola de Enfermagem Anna Nery. Líder de Equipe do Ambulatório do NESA/ Hospital Universitário Pedro Ernesto da Universidade Estadual do Rio de Janeiro-HUPE-UERJ. Professora Assistente do Departamento de Fundamentos de Enfermagem da Faculdade de Enfermagem da UERJ.

${ }^{2}$ Enfermeira. Mestre em Enfermagem. Líder de Equipe do HUPE-UERJ. Coordenadora de Ensino de Enfermagem da MaternidadeEscola da UFRJ.

${ }^{3}$ Doutora em Enfermagem. Bacharel em Filosofia. Especialista em Ética Aplicada e Bioética. Professora Titular da Faculdade de Enfermagem da UERJ. Pesquisadora CNPq.

${ }^{4}$ Internas do $8^{\circ}$ período da Faculdade de Enfermagem da UERJ.

${ }^{5}$ Graduanda do $7^{\circ}$ período da Faculdade de Enfermagem da UERJ.

Autor correspondente:

Inez Silva Almeida

Universidade Estadual do Rio de Janeiro

Rua Rosa e Silva, 60 - 20541-330 - Rio de Janeiro-RJ, Brasil

Recebido: 30/06/09

E-mail: inezdealmeida@ig.com.br

Aprovado: 25/11/09 


\section{INTRODUÇÃO}

A gravidez é um fenômeno que representa uma mudança de papéis para a mulher na sociedade, gerando sentimentos dúbios e contraditórios. Neste sentido, a gestação pode acarretar medos, inseguranças e temores, misturando-se aos sentimentos de alegria, realização, satisfação e contentamento. Estes sentimentos diante da gestação podem ser preponderantes na mulher primípara e estão intrinsecamente relacionados à sua realidade sociocultural, às relações interpessoais e familiares e à situação econômica, podendo interferir, inclusive, no vínculo com o bebê, e posteriormente, no processo de aleitamento materno.

Sabemos que a amamentação é uma prática natural e eficaz, um direito inato do recém-nascido e cujo sucesso depende, em grande parte, das experiências vivenciadas no mundo da mulher e do compromisso e conhecimento técnico-científico e ético dos profissionais de saúde envolvidos.

Neste contexto, faz-se necessário que a equipe de saúde conheça a realidade familiar da mulher para discutir e implementar a atuação de acordo com a vivência da nutriz, não estabelecendo ações baseadas em pressupostos e idéias pré-concebidas ${ }^{(1)}$.

No cotidiano assistencial, encontramos muitas puérperas, mães pela primeira vez, que iniciam a amamentação, mas não se queixam de dificuldades. No entanto, algumas precisam de apoio, incentivo e até mesmo de orientação, pois se sentem inseguras diante do novo desafio de nutrir, apresentando sentimentos ambivalentes que associam poder, feminilidade e medo.

As mães primíparas, na gravidez, no parto ou no puerpério, podem manifestar comportamentos e sentimentos que culminam no aparecimento de crises na vida pessoal e familiar e podem interferir na prática do aleitamento. Dessa forma, o enfermeiro deve apoiálas, agindo como facilitador atento aos indícios de suas necessidades de orientações e cuidados ${ }^{(1)}$

Assim, nos inquietamos sobre: Como o enfermeiro tem lidado com tal realidade? Como tem orientado essas mães primíparas sobre amamentação? $\mathrm{O}$ que o enfermeiro tem em vista ao promover o Aleitamento Materno no contato com as mães primíparas?

Nessa perspectiva, estudos mostram algumas relações conflituosas entre o sistema de saúde, na pessoa do cuidador, e as mulheres, durante o processo gravídico-puerperal. São evidenciadas relações de poder, opressão e controle político sobre as mulheres ${ }^{(1)}$. Portanto, entendemos que o enfermeiro precisa se posicionar diante dos protocolos assistenciais voltados para a amamentação, estabelecendo uma atitude acolhedora, orientadora, e não impositiva ou opressora.

Em muitas culturas as mães naturalmente amamentam; em outras, decidem se irão amamentar ou não antes mesmo do nascimento do seu filho. É fundamental que os profissionais de saúde orientem as mulheres em relação ao aleitamento materno logo no início da gestação, e que identifiquem progenitoras e bebês que podem estar correndo o risco de enfrentar dificuldades no aleitamento materno. Precisamos ter sensibilidade e estar atentos para identificar e agir diante de tais situações. Entretanto, a postura do enfermeiro pode influenciar esse processo(2).

Vale ressaltar que a nossa prática assistencial tem revelado mães primíparas que manifestam o desejo de amamentar, mas requerem orientação e cuidados para a realização deste desejo. Cabe destacar que o enfermeiro é o profissional da equipe de saúde que mais estreitamente se relaciona com a mulher durante o ciclo gravídico-puerperal, lidando com as demandas do aleitamento, atuando nos programas de educação em saúde e orientando a gestante durante o pré-natal.

Esse estudo teve por objeto a orientação do enfermeiro às mães primíparas e por objetivo compreender os motivos-para do enfermeiro ao orientar as primíparas sobre a amamentação.

\section{REVISÃO DE LITERATURA}

\section{Compreendendo a primiparidade na perspectiva da mulher}

A gestação traz para a mãe primípara sentimentos conflituosos que ampliam sua vulnerabilidade emocional, tanto na gestação como durante todo o processo de amamentação. A percepção da maternidade, de acordo com a história de vida desta mulher, se configura como elemento desencadeador de tais sentimentos, pois muitas vezes não conta com o apoio do pai da criança e/ou da própria família ${ }^{(3)}$.

Paralelamente, associado a esse fenômeno, a maternidade é um componente muito valorizado da feminilidade, o que se traduz por um ideal presente na sociedade brasileira de ter o primeiro filho bastante jovem, comparativamente à realidade encontrada em países desenvolvidos ${ }^{(4)}$. As relações sexuais entre 
homens e mulheres são vividas de acordo com a cultura, levando-se em consideração as questões de gênero, atitudes e de papéis claramente atribuídos, e na qual a mulher vivencia a feminilidade através da maternidade e o homem exerce sua masculinidade pela sexualidade.

Não podemos esquecer que as mudanças do mundo contemporâneo não permearam somente a sexualidade e a composição familiar, mas inculcaram na mulher a assunção de um papel no mercado de trabalho que outrora era destinado aos homens. Essa mudança social fez a mulher adiar a decisão da maternidade, ocasionando a primiparidade $\operatorname{tardia}^{(4)}$. Quando refletimos acerca de mães primíparas, somos tentados a pensar nas adolescentes e jovens, mas nossa prática assistencial revela também essa outra realidade.

Essas mães precisam de orientação e um cuidar de enfermagem livre de pressupostos, pois nem sempre a maturidade está relacionada à habilidade maternal para cuidar do recém-nascido e amamentá-lo.

\section{Ações do enfermeiro acerca da amamentação para primíparas}

A amamentação é identificada como um processo natural que sofre influências de diversos fatores biológicos, culturais, demográficos e socioeconômicos, entre outros, e mesmo com todas as vantagens reconhecidas e benefícios largamente demonstrados, a prevalência de aleitamento materno sofreu reduções ao longo das últimas décadas do século $20^{(5)}$. O desmame precoce é um importante problema de saúde pública, em todo mundo, e relacionado a fatores como idade materna, primiparidade, baixo nível de escolaridade, uso precoce de fórmulas lácteas e chupetas, trabalho materno, urbanização, tabagismo, falta de incentivo da família, além de sintomas depressivos da mãe, intercorrências nas mamas, hospitalização da criança, entre outros.

Diversas medidas levadas a efeito nos anos subsequentes foram responsáveis pelo retorno da prática do aleitamento materno ao seu lugar de destaque nos cuidados à saúde da criança. A adoção do Sistema de Alojamento Conjunto para recémnascidos; a modificação da legislação trabalhista visando amparar a gestante e a lactante; a melhoria nos programas de atendimento à gestante e à criança; a criação dos Bancos de Leite Humano; o Método Canguru; a Norma Brasileira de Comercialização de Alimentos para Lactentes, culminando com a Iniciativa Hospital Amigo da Criança e os Dez Passos Para o
Sucesso do Aleitamento Materno, entre outras. Essas iniciativas muito contribuíram para que a amamentação voltasse a desempenhar seu importante papel, proporcionando benefícios diretos e indiretos à sociedade. As recomendações atuais da Organização Mundial de Saúde são de que o aleitamento materno exclusivo alcance os seis primeiros meses de vida da criança, mantendo-se e sendo complementado com outros alimentos até dois anos de idade ${ }^{(6)}$.

Compreendemos que a amamentação não é só uma questão biológica, mas também social, cultural e psicoemocional. Muitas gestantes, já no pré-natal, decidem por não amamentar. O enfermeiro necessita ouvir essas mulheres para tentar compreender o que ocorre no seu mundo cotidiano, desvelando aquilo que está por trás de seus relatos, expressões e condutas; estar atento às demandas oriundas da prática assistencial para identificar a real necessidade das mães primíparas em relação à amamentação. Ainda, deve refletir sobre a orientação de enfermagem, que necessita ser sensível e uniforme no que diz respeito à amamentação. Não basta dizer para a gestante que ela "tem que" amamentar, que o leite materno já possui nutrientes específicos para o bebê, que favorece o vínculo mãe e filho, que não tem custo nenhum, entre tantas outras vantagens. As informações sobre a amamentação exigem a efetivação do cuidar de modo empático, integral, sem preconceitos ou pressupostos e que permitam adentrar no mundo da vida da primípara, tentando compreender as relações sociais que influenciaram no desenvolvimento do aleitamento materno.

\section{METODOLOGIA}

Para realização e desenvolvimento desse estudo, estabelecemos como método a fenomenologia sociológica de Alfred Schütz.

A fenomenologia não indaga a causa da vivência da cliente, mas sim, o significado do ser e suas ações intencionais, durante sua existência. É uma abordagem metodológica que não se direciona aos porquês, busca ver, cada vez mais profundamente, descrevendo com toda fidelidade, as vivências dos sujeitos. Esta descrição é realizada através do olhar direcionado e penetrante para o fenômeno, pela intuição, atingindo assim a essência do ato emanado da consciência ${ }^{(7)}$.

Schütz encontra na fenomenologia uma teoria coerente com o significado de subjetividade, da intersubjetividade e da intencionalidade da consciência. 
Tais concepções constituíram as bases filosóficas para que Schütz elaborasse a fenomenologia sociológica ${ }^{(8)}$.

Neste sentido, podemos afirmar que a filosofia de Alfred Schütz articula uma intuição: o descobrimento, em sua profundidade, das estruturas e significados do mundo do sentido comum. Mundo do sentido comum, mundo da vida, mundo cotidiano, são diversas expressões que indicam o mundo intersubjetivo experienciado pelo homem. Este mundo é existente antes mesmo do nosso nascimento, já possui uma história e nos é dada, mostrada de maneira organizada. É neste mundo cotidiano que ocorrem as relações sociais, as experiências e vivências que o método de Schütz busca compreender ${ }^{(9)}$.

No contexto da prática do cuidado às mães primíparas, o enfermeiro orienta a partir das relações estabelecidas neste cenário, celeiro de vivências e experiências dessas mulheres.

O homem é o principal ator social deste mundo da vida. O modo como ele desenvolve suas ações, interpreta suas possibilidades e enfrenta seus desafios, são definidos pela sua situação biográfica. A Situação biográfica é definida por Schütz como o ambiente social, cultural e físico, dentro do qual o homem tem sua posição e exerce seu papel neste contexto, com ações no sistema social, com postura ideológica e moral. Corresponde à sedimentação de toda experiência vivida pelo indivíduo ${ }^{(10)}$.

Quando orientamos e estimulamos uma puérpera a amamentar, precisamos compreender que tipo de relação e influência seus predecessores, contemporâneos e associados, exercem sobre ela contribuindo para sua decisão de amamentar ou não. Compreendemos que ela não é um ser isolado neste mundo da vida, mas está o tempo todo se relacionando com o outro e que, muitas vezes, essa relação definirá suas ações. Só através da intersubjetividade conseguimos desenvolver uma relação face a face com a mãe primípara, contribuindo e desenvolvendo um cuidar empático.

Schütz define Ação como a conduta humana realizada pelo indivíduo de maneira autoconsciente. Por outro lado, o termo Ato designa a ação a ser realizada. A ação se origina na consciência do ator ${ }^{(11)}$.

Para compreender a ação subjetiva do indivíduo, Schütz ${ }^{(9)}$ utiliza termos como motivos-para ou em vista de e motivos-porque, definindo-os como: motivospara referente aos objetivos que são intencionados, projetos e ações a serem realizadas, ações voltadas para o futuro, relacionados com a consciência do ator, formam uma categoria subjetiva. Já motivos-porque são perceptíveis nos acontecimentos que já ocorreram, explicam etapas realizadas no projeto, referentes às ações do passado. Consiste numa categoria objetiva ${ }^{(12)}$.

A fenomenologia, nesse estudo, constituiu-se em uma possibilidade metodológica para aqueles que buscam aprofundar conhecimentos ou obter uma base teórico-filosófica de sua prática no aleitamento materno.

Nesse sentido, os atores do estudo foram 12 enfermeiros que atuam no alojamento-conjunto da Maternidade-Escola da Universidade Federal do Rio de Janeiro, cenário desta pesquisa. Utilizamos como critérios de inclusão o desejo de participar do estudo e a atuação desses enfermeiros no cuidado direto às primíparas internadas nessa instituição no período do puerpério.

A aprovação do Comitê de Ética em Pesquisa da instituição se deu em parecer consubstanciado sob o no 13/2009 CAAE 0015.0.361.000-09. Após a autorização, através da assinatura do Termo de Consentimento Livre e Esclarecido, foi iniciada a fase de campo, respeitando-se as normas éticas da pesquisa com seres humanos, conforme a Resolução 196/96 ${ }^{(13)}$.

A investigação ocorreu no período de abril a junho de 2009, através da técnica de entrevista fenomenológica. Para a coleta dos dados foi realizada a gravação dos depoimentos, após a autorização dos participantes. A captação das falas foi permeada pela empatia, que permitiu o mostrar-se dos profissionais acerca da sua visão de mundo sobre o fenômeno. Os dados revelaram os motivos-para dos enfermeiros mediante a ação de orientar mães primíparas sobre a amamentação. Ao término da entrevista, foi perguntado aos enfermeiros quais sentimentos destacariam como predominantes nas mães primíparas durante o aleitamento materno e, assim, cada enfermeiro escolheu um desses sentimentos como codinome para si, em respeito ao anonimato.

Mediante a questão orientadora da entrevista O que você tem em vista ao orientar mães primíparas sobre a amamentação? - apreendemos os motivospara de enfermeiros que desenvolvem essa prática assistencial no seu cotidiano profissional, como um projeto intencional do grupo de trabalho.

A leitura minuciosa do material não estruturado teve como finalidade captar a repetição dos aspectos comuns das falas dos enfermeiros do estudo. Tais aspectos direcionaram para a apreensão das categorias concretas do vivido, frente às questões sociais surgidas 
com a prática assistencial, através das orientações sobre o aleitamento materno para primíparas.

As categorias concretas foram formuladas a partir da apreensão pelo pesquisador dos significados comuns expressos pelos sujeitos do estudo. Essas categorias contêm as estruturas subjetivas de sentido, ou seja, os significados que os sujeitos atribuem à sua própria ação ${ }^{(12)}$.

\section{ANÁLISE COMPREENSIVA}

No cotidiano hospitalar nem sempre a vivência assistencial, as rotinas, a administração gestora e a prática nos permitem refletir acerca das ações que temos em vista e que objetivamos, ao ministrar o cuidado. Daí a necessidade de estudos que deem voz àqueles que desenvolvem orientações sobre o aleitamento materno para as primíparas, na perspectiva da adequação dessa ação à realidade das mães e dos recém-nascidos.

Para a Análise Compreensiva, a importância e veracidade dos depoimentos não se dão de forma individualizada com referência intrínseca à pessoa. As vivências não são tipicamente exclusivas de um indivíduo, mas de algumas pessoas que vivenciam o fenômeno de cuidar de mães primíparas mediante a ação da amamentação.

Na síntese tipificante de reconhecimento, realizamos ato de anonimização, no qual abstraimos a vivência do marco da corrente da consciência e, portanto, a fazemos impessoal ${ }^{(10)}$.

Assim sendo, apresentamos a seguir as categorias que emergiram das falas.

\section{Incentivar a amamentação}

Estimular o aleitamento materno exclusivo é foco de atenção dos enfermeiros que atuam na área materno-infantil, na perspectiva obstétrica, pois já está bem sedimentado o conhecimento das vantagens da amamentação e do leite humano. A literatura retrata a importância do aleitamento materno como prática ideal para a saúde da mulher e necessária para a nutrição infantil, levando ao crescimento e desenvolvimento da criança .

Esta primeira categoria nos faz refletir sobre a prática do enfermeiro, que durante a assistência demonstra sua intencionalidade em auxiliar a mãe inexperiente no processo da amamentação. A manutenção da amamentação exclusiva é marcada pela vivência inicial da mãe com a prática do aleitamento materno. Se essa vivência for negativa para a puérpera, provavelmente ela terá dificuldades na manutenção da amamentação exclusiva, principalmente em se tratando da primiparidade ${ }^{(14)}$.

A intencionalidade do enfermeiro em orientar a primípara, incentivando-a a amamentar, revela uma assistência fundamentada, voltada para o futuro, quando esta mãe já estará em seu domicílio. O motivo-para demonstrado nesta categoria mostra um enfermeiro com uma ação intencional não restrita ao período da hospitalização, pois não se limita às orientações acerca das vantagens do aleitamento materno, assim como às questões biológicas desta ação, mas o incentivo revela também as questões socioemocionais desse processo:

[...] a amamentação tem grande influência depois no desenvolvimento da criança, e a gente procura ao máximo incentivar, ter paciência, para que o bebê possa mamar exclusivamente até os seis meses (MEDO).

[...] oriento como deve ser a amamentação, o que é ideal, como deve ser a pega [...] (AMOR).

[...] e também pela involução uterina a gente já estimula, principalmente se for cesárea. Então, logo que a puérpera chega, a gente coloca o bebê pra sugar, pra ver a suç̧ão dele e pra facilitar o contato, ver como ele fica, até porque, quanto mais cedo for feito isso, é melhor, mais rápido a mãe e o bebê conseguem se adaptar [...] mas temos que sensibilizar, incentivar (TEMOR).

O estudo revelou uma preocupação por parte dos enfermeiros ao orientar, na intencionalidade de estimular o aleitamento materno. Entretanto, o sujeito da pesquisa também alerta sobre as prováveis dificuldades e/ou complicações acerca da amamentação.

\section{Alertar sobre as dificuldades e complicações da amamentação}

Os participantes revelaram os motivos-para através das informações sobre as complicações diante do aleitamento materno, já nas orientações iniciais.A dificuldade para amamentar nos primeiros dias, mostrase fortemente associada ao desmame, independente de 
outros fatores ${ }^{(14)}$. É atribuição do profissional de saúde prestador da assistência a mulheres e crianças promover o aleitamento materno, na sua forma ampliada, através de ações que tenham por objetivo a sensibilização, promoção, incentivo e apoio a esta prática.

Compreendendo a amamentação como um complexo que envolve a cultura, o valor, o social, o biológico e emocional, deve-se ir além das orientações quanto ao manejo. O profissional pode cuidar da mãe primípara na perspectiva de estimular a amamentação exclusiva, evitando o desmame precoce. Por isso, é fundamental que o enfermeiro não cuide somente com abordagem técnica, mas que sua perspectiva seja ampliada, através de uma assistência associada aos aspectos socioculturais da amamentação:

\section{[...] a gente procura identificar as principais} dificuldades dessa mulher no posicionamento do $R N$, as principais dificuldades dela na pega correta da criança (SATISFAÇÃO).

Falo da pega correta, sobre a mastite, evitar fissuras, faço as orientações necessárias (INSEGURANÇA).

[...] então, a gente tenta trabalhar nesse contexto do que é ser mãe, do que é amamentar esse bebê pela primeira vez, do que é passar por fissuras, dor ao amamentar, vencer esses desafios, sobrepor essas dificuldades pra conseguir amamentar. Boa parte delas passa por problemas, porque a pele do mamilo não está acostumada com esse ritmo de sucção do bebê, dificuldades em manejar esse neném pra colocar ele pra sugar. Todas essas coisas fazem com que possa ter uma dificuldade na pele e tenha fissuras, engurgitamento, essas coisas que são difíceis para as mães primíparas. Então, a gente tenta trabalhar essa vivência, tentando tirar essas dificuldades, trocando e compartilhando vivências, promovendo uma relação de ajuda (ALEGRIA).

Daí a importância dos profissionais estabelecerem uma relação face a face com a mãe primípara em sua singularidade, possibilitando uma tomada de decisão positiva para a amamentação.

\section{CONSIDERAÇÕES FINAIS}

As categorias que emergiram das falas revelaram a intencionalidade dos profissionais enfermeiros que experimentam o fenômeno da amamentação mediante a convivência, no mundo da vida da prática profissional, com mães primíparas.

Nesse contexto, as ações do indivíduo dependerão de sua interação com os outros sujeitos, consigo mesmo e sua cultura. Como enfermeiros, necessitamos compreender o mundo da mãe primípara e guiar nossas ações para sua realidade social e cultural.

Ao cuidar de mães primíparas assumimos a posição de contemporâneos destas, mas a forma como elas lidam com o fenômeno da amamentação pode ser fortemente influenciada pelas experiências compartilhadas com seus predecessores. Desta maneira, o cuidador precisa se relacionar de modo empático, para adentrar no mundo da vida desta mãe, na tentativa de auxiliar no processo do aleitamento materno.

O estudo tem aplicabilidade na prática profissional da enfermagem por mostrar a possibilidade da realização de um cuidado voltado para as necessidades da cliente, vislumbrando a reflexão sobre o agir-cuidar na vida cotidiana da mãe primípara. Nesse sentido, podemos apreender que a prática da enfermagem está contextualizada na intencionalidade do profissional, visando melhor assistir a esta mãe. No que se refere à prímipara, a ação intencional do enfermeiro está relacionada à promoção e apoio à amamentação, ressaltando que não basta orientar: é importante o acompanhamento com diálogo, visando à qualidade do cuidado.

Desta forma, percebe-se o enfermeiro envolvido com o processo da amamentação para primíparas no seu cotidiano assistencial, onde suas ações são pensadas, planejadas e executadas no sentido de viabilizar o aleitamento materno dentro da realidade da primiparidade. Esta prática reflete a singularidade da ação deste profissional ao incentivar a amamentação, alertando sobre as dificuldades e complicações.

\section{REFERÊNCIAS}

1. Araújo OD, Cunha AL, Lustosa LR, Nery IS, Mendonça RCM, Campelo SMA. Aleitamento materno: fatores que levam ao desmame precoce. Rev Bras Enferm. $2008 \mathrm{Jul} /$ Ago;61(4):488-92

2. Ministério da Saúde (BR). Programa Nacional de Incentivo ao Aleitamento Materno. Grupo de Defesa da Saúde da Criança. Manejo e Promoção ao Aleitamento Materno. Curso para equipes de maternidades. Brasília; 1993.135p. 
3. Ramos CV, Almeida JAG. Aleitamento materno: como é vivenciado por mulheres assistidas em uma unidade de saúde de referência na atenção materno-infantil em Teresina, Piauí. Rev Bras Saude Mater Infant 2003. Jul/ Set; 3(3). doi: 10.1590/S1519-38292003000300010.

4. Heilborn ML, Cabral CS. Parentalidade juvenil: transição condensada para a vida adulta. In: Camarano AA, organizador. Transição para a vida adulta ou vida adulta em transição? Rio de Janeiro: IPEA;2006.

5. Sales C, Seixas S. Causas de desmame precoce no Brasil. Cogitare Enferm. 2008 Jul/Set; 13(3):443-7.

6. Issler $\mathrm{H}$. O aleitamento materno no contexto atual: políticas, prática e bases científicas. São Paulo: Sarvier; 2008. 627p.

7. Capalbo C. Fenomenologia e ciências humanas. $3^{\mathrm{a}}$ ed. Londrina: UEL; 1996. 133 p.

8. Panizza L. Da sociologia compreensiva de Max Weber à sociologia fenomenológica de Alfred Schütz. 1980. [dissertação]. Rio de Janeiro (RJ): Universidade Federal do Rio de Janeiro; 1980.

9. Schütz A. El problema de la realidad social. Buenos Aires: Amorrortu; 1974.

10. Schütz A. A fenomenologia del mundo social: introducción a la sociologia compreensiva. Buenos Aires: Paidós: 1972.

11. Rodrigues BMRD. O cuidar de crianças em creche comunitária: contribuição da sociologia fenomenológica de Alfred Schütz. Londrina: UEL;1998.

12. Jesus MCPA. Educação sexual na vida cotidiana de pais e adolescentes: uma análise compreensiva da ação social. [tese]. São Paulo (SP): Universidade de São Paulo;1998.

13. Ministério da Saúde (BR). Conselho Nacional de Saúde, Comissão Nacional de Ética em Pesquisa. Resolução 196 de 10 de outubro de 1996: diretrizes e normas regulamentadoras de pesquisa envolvendo seres humanos. Brasília; 1996.

14. Frota DAL, Marcopito LF. Amamentação entre mães adolescentes e não-adolescentes. Montes Claros MG. Rev Saúde Pública. 2004 Fev; 38(1):85-92. 